\title{
Audiodescrição das imagens dos livros didáticos: uma proposta de análise comunicacional
}

\author{
Audiodescription of images of textbooks: a proposal for communicational \\ analysis
}

Audiodescripción de las imágenes de los libros didácticos: una propuesta de análisis comunicacional

\author{
* Deise Mônica Medina Silveira \\ Professora doutora no Instituto Federal da Bahia (IFBA), Salvador, Bahia, Brasil. \\ deisemoni@gmail.com \\ ** Maria Helena Silveira Bonilla \\ Professora doutora na Universidade Federal da Bahia (UFBA), Salvador, Bahia, Brasil. \\ bonillabr@gmail.com
}

Recebido: 01 de julho de 2018

Aprovado: 15 de outubro de 2018

\section{RESUMO}

Após a Lei 10.753/2003 ter assegurado às pessoas com deficiência visual o acesso à leitura, e o Decreto 186/2008 ter atribuído ao Estado a responsabilidade de assegurar-Ihes, inclusive, o acesso à informação, em 2009 o Ministério da Educação lançou o Mecdaisy, que possibilita a geração de livros digitais falados e sua reprodução em áudio, gravado ou sintetizado. A partir daí os alunos das redes municipal e estadual passaram a receber os livros didáticos em formato digital acessível. O meio de tradução das imagens dos livros didáticos é a audiodescrição, que é orientada pela Nota Técnica 21, composta por procedimentos basicamente descritivos. Neste artigo é proposta a incorporação de aspectos analíticos às audiodescrições, a partir das metafunções representacional, interacional e composicional propostas pela Gramática do Design Visual de Kress e van Leeuwen, com o objetivo de dar aos alunos com deficiência visual subsídios para que eles interpretem aspectos do significado ideológico das imagens, tendo, assim, uma maior apropriação da mensagem contida no gênero imagético.

Palavras-chave: Audiodescrição; Livro Didático; Deficiência Visual.

\section{ABSTRACT}

After the Law 10,753/2003, which ensured the visually impaired the access to reading, and the Decree $186 / 2008$, which gave the State the responsibility to ensure them access to 


\section{DOI: $10.5902 / 198468627720$}

information, in 2009 the Ministry of Education launched the Mecdaisy, which enables the generation of spoken digital books and their reproduction in audio, recorded or synthesized. From then on, the students of the municipal and state schools began to receive the textbooks in accessible digital format. The medium for translating textbook images is audio description, which is guided by the Technical Note 21 composed of descriptive procedures. In this article is proposed the incorporation of analytical aspects to the audio descriptions, from the representational, interactional and compositional metafunctions proposed by the Visual Design Grammar of Kress and van Leeuwen, aiming to give students, with visual impairment, subsidies, so that they interpret aspects of ideological meaning of the images, having a greater appropriation of the message contained in the imagery genre.

Keywords: Audio description; Textbook; Visual impairment.

\section{RESUMEN}

Después de la Ley 10.753 / 2003 haber asegurado a las personas con discapacidad visual el acceso a la lectura, y el Decreto 186/2008 atribuyó al Estado la responsabilidad de asegurarles, incluso, el acceso a la información, en 2009 el Ministerio de Educación lanzó el " Mecdaisy, que posibilita la generación de libros digitales hablados y su reproducción en audio, grabado o sintetizado. A partir de ahí los alumnos de las redes municipal y estatal pasaron a recibir los libros didácticos en formato digital accesible. El medio de traducción de las imágenes de los libros didácticos es la audiodescripción, que está orientada por la Nota Técnica 21, compuesta por procedimientos básicamente descriptivos. En este artículo se propone la incorporación de aspectos analíticos a las audiodescripciones, a partir de las metafunciones representacional, interactiva y composicional propuestas por la Gramática del Diseño Visual de Kress y van Leeuwen, con el objetivo de dar a los alumnos con deficiencia visual subsidios para que ellos interpreten aspectos del proceso, el significado ideológico de las imágenes, teniendo así una mayor apropiación del mensaje contenida en el género imagético. Palabras clave Audiodescripción; Libro Didáctico; Deficiencia visual.

\section{Introdução}

Após a Lei 10.753/2003, que institui a Política Nacional do Livro, e que, em seu Artigo $1^{\circ}$, inciso XII, assegura às pessoas com deficiência visual o acesso à leitura, no ano de 2008 surgiu o Decreto 186 que, em seu Artigo 9², afirma que "a fim de possibilitar às pessoas com deficiência viver de forma independente e participar plenamente de todos os aspectos da vida, os Estados Partes devem tomar as medidas apropriadas para assegurar às pessoas com deficiência o acesso, em igualdade de oportunidades com as demais pessoas, ao meio físico, ao transporte, à informação e comunicação". No ano de 2009 , em cumprimento às exigências supracitadas, o Ministério da Educação apresentou o Mecdaisy, 


\section{DOI: $10.5902 / 198468627720$}

uma solução tecnológica que possibilita a geração de livros digitais falados e sua reprodução em áudio, gravado ou sintetizado, desenvolvida em parceria com o Núcleo de Computação Eletrônica da Universidade Federal do Rio de Janeiro (NCE/UFRJ).

Esses livros são distribuídos pelo Programa Nacional do Livro Didático (PNLD), para as escolas municipais e estaduais de todo o país, que registram matrículas de alunos com deficiência visual. As imagens dos livros digitais são traduzidas em palavras através do recurso da audiodescrição, e os procedimentos para as descrições são regimentados pela Nota Técnica 21 (MEC/SECADI/DPEE), publicada em 10 de abril de 2012, pela Secretaria de Educação Continuada, Alfabetização, Diversidade e Inclusão do Ministério da Educação.

Tais procedimentos orientam as descrições com base em normas da audiodescrição, encontradas em manuais de países da Europa e dos Estados Unidos, que se aplicam, principalmente, a imagens dinâmicas, o que as diferenciam das imagens dos livros didáticos que têm caráter estático. Contudo, essas normas se concentram em orientar a descrição do que é visto nas imagens, sem considerar o valor simbólico e ideológico que elas carregam e através do qual se comunicam com o contexto e com o seu propósito.

Portanto, este artigo tem por objetivo discutir como tornar as descrições mais completas a partir da incorporação de aspectos comunicacionais às orientações de elaboração das audiodescrições das imagens dos livros didáticos.

\section{Linguagem visual}

As representações visuais nos remetem a significados e conceitos diversos com os quais estabelecemos uma série de relações e fazemos inferências. De acordo com Perez (2008, p. 176), as imagens têm sua própria linguagem, formada por elementos plásticos como pontos, linhas, cores, formas, texturas, etc., que são elementos expressivos, "são pistas que fazem com que coloquemos em cena os nossos sentidos" (Ibidem, p. 165). Segundo o autor:

A imagem não se presta à comunicação objetiva ou à pura descrição apenas de fatos e ideias, de conhecimentos determinados pela razão lógica, mas ao conhecimento sensível, só obtido pelas emoções que não encontram paralelo no verbal, exceto pela poesia que remete à imagem como um retorno ou uma tábua de salvação às incongruências das palavras. (PEREZ, 2008, p. 208)

Ao analisar os significados da arte renascentista, o historiador Panofsky (1955 apud LIU, 2013, p. 1261) identificou os significados convencionais e os filosóficos subjacentes às imagens, assim como as interpretações construídas dentro do contexto sociocultural dado, e identificou três níveis de significado. O primeiro nível, pré-iconográfico, é o nível 


\section{DOI: $10.5902 / 198468627720$}

denotativo, "focado principalmente na interpretação do significado elementar ou natural, que envolve a identificação de materiais visuais, tais como os objetos conhecidos da experiência diária". Neste nível, o que está representado na imagem, seus objetos, fenômenos ou ambiente, é descrito de forma simples e direta. O segundo nível, iconográfico, é o nível conotativo, "centrado principalmente na interpretação de significados secundários ou tradicionais e, durante o processo interpretativo, os espectadores precisam ir além do significado natural ou superficial da imagem para considerar seus conhecimentos e experiências". Este nível, segundo Liebel (2011, p. 3), "é constituído da interpretação das ações e gestos que se passam na imagem de modo a encontrar um sentido geral para eles, a apreensão de sua natureza de acordo com o senso comum". E o terceiro nível, iconológico, "centra-se principalmente na interpretação de significados ideológicos de uma imagem construída em contextos sociais, culturais, políticos e históricos particulares". Neste nível, de acordo com Liebel (2011, p. 4), ocorre "a interpretação da imagem através do estudo de sua singularidade como fonte histórica e social".

Juntos, esses três níveis de significado são responsáveis pela composição de sentido da linguagem visual, a qual chega ao público vidente através da visão que, por sua vez, aciona o conhecimento e os mecanismos necessários para que ocorram as inferências e, através da audição que, em muitos casos, complementa ou dá pistas à informação visual.

Quando se trata do público com deficiência visual, o conhecimento e os mecanismos de inferência serão acionados unicamente pelo input verbal, ou seja, pelas informações que Ihe chegam acerca da imagem; é através destas informações que o público em questão construirá sentido sobre o texto imagético.

Logo, a descrição das imagens dos livros didáticos, através da audiodescrição, deve dar aos deficientes visuais, além das informações situacionais e circunstanciais da linguagem verbal, subsídios para que eles tenham acesso à expressividade dos elementos plásticos que compõem as imagens, ampliando, assim, sua possibilidade de compreensão da simbologia e ideologia próprias das representações visuais.

\section{Audiodescrição}

Imagens, dinâmicas ou estáticas, são elementos constitutivos da nossa realidade e estão presentes em todos os lugares e meios de comunicação aos quais temos acesso. No contexto escolar, elas se apresentam de forma sistemática nos livros didáticos como 
fotografias, gráficos, ilustrações, tabelas, tirinhas cômicas, cartuns, charges, mapas, etc., levando os alunos a diferentes leituras e abstrações.

Logo, no livro didático, encontramos textos verbais e não verbais, ou imagéticos, distribuídos em seus diversos gêneros, aos quais os alunos sem deficiência sensorial têm pleno acesso, o que lhes permite, de acordo com o seu grau de letramento, estabelecer relações contextuais e produzir sentidos para além da decodificação do texto verbal.

Os alunos com deficiência visual também têm acesso a todos os gêneros textuais do livro didático, mas pelo sentido da audição, através da audiodescrição/tradução desses textos. Esses inputs são a fonte para que eles estabeleçam relações contextuais e produzam sentidos para além da decodificação do texto verbal que lhes chega.

A audiodescrição, ou $A D$, é um modo de tradução intersemiótica, que traduz em palavras informações visuais estáticas (ex. obras de arte, ilustrações, etc.), e informações dinâmicas (ex. filmes, clipes, etc.), para que conteúdos-chave, transmitidos visualmente, não passem despercebidos e possam também ser acessados por pessoas cegas ou com baixa visão, congênita ou adquirida, além de atender também a pessoas com deficiência intelectual e dislexia. (FRANCO et al., 2013)

Enquanto ferramenta de acessibilidade, a audiodescrição se classifica como uma tecnologia assistiva, que, de acordo com o Comitê de Ajudas Técnicas, é uma:

[...] área do conhecimento, de característica interdisciplinar, que engloba produtos, recursos, metodologias, estratégias, práticas e serviços que objetivam promover a funcionalidade, relacionada à atividade e participação de pessoas com deficiência, incapacidades ou mobilidade reduzida, visando sua autonomia, independência, qualidade de vida e inclusão social. (CAT, 2007c)

$\mathrm{Na}$ acessibilidade às imagens do livro didático, a $A D$ viabiliza uma maior autonomia e independência dos alunos com deficiência visual, pois minimiza suas perdas em relação aos alunos videntes, uma vez que ela lhes permite vivenciar, guardados os devidos graus de subjetividade de cada um, uma maior experiência e compreensão do conteúdo visual do livro. Para tanto, a elaboração da audiodescrição destas imagens é orientada pelos procedimentos da Nota Técnica 21 do Ministério da Educação.

\section{Nota técnica 21 do MEC}

Os alunos com deficiência visual da rede pública passaram a ser contemplados no Programa Nacional do Livro Didático a partir do ano 2000/2001 com livros didáticos em braile. Após a Lei 10.753/2003, da Política Nacional do Livro, e do Decreto 186 do ano de 


\section{DOI: $10.5902 / 198468627720$}

2008, o MEC apresentou o Mecdaisy no ano de 2009, e os alunos das redes municipal e estadual passaram a receber os livros didáticos em formato digital acessível.

Inicialmente, o MEC atribuiu aos 55 Centros de Apoio Pedagógico - CAP - a responsabilidade pela produção dos livros didáticos em formato acessível para os alunos com deficiência visual dos anos finais da Educação Fundamental e do Ensino Médio das redes estadual e municipal. A partir da sanção do Decreto 7084/2010, revogado pelo Decreto 9099/2017, os editais dos programas de materiais didáticos passaram a prever obrigações para as editoras no que diz respeito à entrega das versões impressas e digitais dos livros selecionados pelas escolas, retirando dos CAP a responsabilidade pela sua produção.

Com o propósito de padronizar as descrições das imagens dos livros digitais, a Secretaria de Educação Continuada, Alfabetização, Diversidade e Inclusão do Ministério da Educação publicou a Nota Técnica 21. Esta Nota traz procedimentos que têm como premissa a importância das audiodescrições contemplarem aspectos como: o quê/quem identificação do sujeito, objeto ou cena; onde - localização do sujeito, objeto ou cena; como - qualificação e descrição da ação do sujeito, objeto ou cena; e quando - explicitação do tempo em que ocorre a ação. Além disso, as descrições devem "mencionar as imagens de fundo, detalhes, caixas de texto, bordas coloridas que aparecem na página, na parte inferior, pois os recursos gráficos utilizados traduzem a intenção do autor" (NOTA TÉCNICA 21, item 18). A Nota traz, também, orientações sobre técnicas de descrição do enquadramento da imagem, destaca a importância de identificar a fonte das imagens através de legendas, assim como da adequação de termos à área de conhecimento. O documento ainda apresenta orientações sobre aspectos gramaticais que devem ser levados em consideração, define procedimentos sobre a descrição de charges, cartuns, tirinhas cômicas, tabelas, fluxogramas, organogramas e encerra com exemplos de diferentes tipos de imagens audiodescritas.

Os procedimentos da Nota Técnica 21 baseiam-se nas diretrizes e práticas regulamentadas por manuais lançados em países da Europa, como Alemanha (German $A D$ Guidelines, 2004), Reino Unido (ITC Guidance On Standards for Audio Description, 2000) e Espanha (UNE 153020, 2005), e dos Estados Unidos, (Audio Description Coalition, 2007, e American Council of the Blind's Audio Description Project, 2009). No Brasil, temos as 
Normas Brasileiras ABNT NBR 152690 de 2005 e a ABNT NBR 16542 de 2016, que preveem acessibilidade em comunicação na TV.

Esses parâmetros são essenciais para que os alunos com deficiência visual compreendam o conteúdo da imagem, porém, como afirmam Bezerra e Porpino (2015, p. 240), "toda imagem é prenhe de significados e sentidos"; logo, tais parâmetros não dão subsídios para que o aluno com deficiência visual compreenda o valor simbólico e ideológico dos textos imagéticos, pois seguem as orientações das normas acima, que são regidas pelo princípio da objetividade proposto por praticantes e estudiosos como Joel Snyder, que afirma que "O melhor audiodescritor é, às vezes, visto como uma "lente de câmera verbal", contando objetivamente aspectos visuais de um evento". E sugere, "deixe que os ouvintes evoquem suas próprias interpretações com base em um comentário que seja tão objetivo quanto possível" (SNYDER, 2014, p. 43).

Reiterando este princípio, o ITC Guidance On Standards for Audio Description, um dos maiores compêndios de melhores práticas para a $A D$, afirma que "descritores não devem verbalizar opinião pessoal ou interpretar eventos” (2000, p. 15). Snyder (2014, p. 14) faz referência ao princípio WYSWYG (What You See Is What You Get), como sendo a regra número um das descrições, que determina que, ao descrever as imagens, o audiodescritor deve se limitar exclusivamente ao que vê e evitar interpretações subjetivas.

Na maioria dos países da Europa e dos Estados Unidos, os roteiros de AD são feitos a partir deste princípio; contudo, já existem muitos estudos que questionam a possibilidade da interpretação objetiva, uma vez que o ato de traduzir implica subjetividade. A partir desta compreensão, e cientes que somos da riqueza de significados presentes nas imagens, propomos a incorporação de aspectos da Gramática do Design Visual, proposta por Kress e van Leeuwen (1996, 2006), que leva em conta práticas sociais culturalmente especificadas ao combinar seus elementos sintáticos e suas partes em todos significativos.

\section{Gramática do design visual}

Para que as descrições contemplem também as representações simbólicas e ideológicas das imagens, dentro do contexto social no qual os alunos estão inseridos, propomos a incorporação dos princípios de leitura de imagens da Gramática do Design Visual (GDV), desenvolvida por Kress e van Leeuwen $(1996,2006)$, às audiodescrições das 
imagens dos livros didáticos. A Gramática do Design Visual baseia-se na teoria da Gramática Sistêmico-Funcional (GSF), de Halliday (1985, 1994, 2004).

Kress e van Leeuwen veem quaisquer imagens como meios para a articulação de posição ideológica. Para eles, a maioria dos estudos da semiótica visual tem se concentrado no que poderia ser considerado o equivalente a "palavras", ao que os linguistas se referem por "léxico", focando no sentido denotativo e conotativo dos elementos da imagem, e não na gramática ou na sintaxe que surgem a partir de seus elementos constitutivos, mostrando como eles se combinam em todos significativos (KRESS; VAN LEEUWEN, 2006, p. 1).

A proposta de Kress e van Leeuwen para a análise de imagens, utilizando os aportes da GSF, não tem como objetivo encontrar correspondentes entre as estruturas linguísticas e visuais, pois os autores afirmam que esses dois meios "não são simplesmente alternativas de representação da "mesma coisa"” (KRESS; VAN LEEUWEN, 2006, p. 76), já que cada um tem seus próprios códigos e regras para isso.

Halliday (1985, 1994 apud KRESS; VAN LEEUWEN, 2006, p. 42-43) propõe três funções para a linguagem, que mostram as finalidades e os propósitos da comunicação: a função ideacional, que representa aspectos do mundo como são experimentados pelas pessoas, ou seja, essa função deve representar os objetos e suas relações no mundo externo ao sistema representacional. A função interpessoal, que projeta as relações entre o produtor de um signo (complexo) e o receptor/reprodutor deste signo, ou seja, representa uma relação social particular entre o produtor, quem visualiza o objeto e o objeto representado. E a função textual, que é responsável por textos complexos de signos coerentes entre si e com o contexto para o qual foram produzidos.

Kress e van Leeuwen (2006) afirmam que as imagens também expressam significados através dessas metafunções e as renomeou para função representacional, interacional e composicional, respectivamente. A função representacional é responsável pelas estruturas que constroem visualmente a "natureza dos eventos, objetos e participantes envolvidos, e as circunstâncias em que ocorrem" Unsworth (2004 apud NOVELLINO, 2007, p. 53). Ela é responsável por indicar o que está sendo mostrado - ou aquilo que o espectador supõe que esteja acontecendo. 


\section{DOI: $10.5902 / 198468627720$}

Kress e van Leeuwen (1996 apud JEWITT; OYAMA, 2001, p. 141) descrevem padrões visuais sintáticos de acordo com sua função de relacionar os participantes visuais entre si de maneiras significativas. Segundo eles, há dois tipos de padrão:

As representações narrativas relacionam os participantes em termos de "feitos" e "acontecimentos", do desenrolar de ações, eventos ou processos de mudança. Os padrões conceituais representam os participantes em termos das suas "essências" mais generalizadas, estáveis ou intemporais. Eles não os representam como fazendo algo, mas como sendo algo, ou significando algo, ou pertencendo a alguma categoria, ou tendo certas características ou componentes. A escolha é importante, pois a decisão de representar algo de forma narrativa ou conceitual fornece uma chave para a compreensão dos discursos que medeiam sua representação. (KRESS; VAN LEEUWEN,1996 apud JEWITT; OYAMA, 2001, p. 141)

$\mathrm{Na}$ função interacional, os recursos visuais constroem "a natureza das relações de quem vê e o que é visto" Unsworth (2004 apud NOVELLINO, 2007, p. 53). De acordo com Jewitt e Oyama (2001, p, 145) "as imagens podem criar relações particulares entre os espectadores e o mundo imagético. Desta forma, elas interagem com os observadores e sugerem que atitude estes devem ter em relação ao que está sendo representado". Três fatores desempenham papel fundamental na realização desses significados: contato, distância e ponto de vista.

Do ponto de vista do contato, tomando como exemplo imagens que mostram pessoas olhando diretamente para o espectador, Kress e van Leeuwen (1996) entendem que elas "fazem contato" com o espectador, estabelecem uma relação imaginária. Eles chamam essas imagens de "imagens de demanda", pois as pessoas, simbolicamente, demandam algo do espectador.

No que diz respeito à distância, as imagens podem aproximar ou afastar pessoas, lugares e objetos dos espectadores. De acordo com Jewitt e Oyama (2001, p.146) "na nossa interação diária, as normas das relações sociais determinam a distância que mantemos uns dos outros. Isto se traduz no "tamanho do quadro" das fotos", que pode ser descrito conforme terminologia usada na TV:

Um close-up (cabeça e ombros ou menos) sugere um relacionamento íntimo/pessoal; um close médio (cortando a figura humana em algum lugar entre a cintura e os joelhos) sugere uma relação social; e um "close longo" (mostrando a figura completa, seja apenas encaixando no quadro ou ainda mais distante) sugere uma relação impessoal. (JEWITT; OYAMA, 2001, p. 146)

O ponto de vista ou perspectiva na qual a imagem é mostrada implica na possibilidade de expressar atitudes subjetivas em relação aos participantes representados. Contudo, essas "atitudes subjetivas" não são individuais. Kress e van Leeuwen (2006, p. 129) 
argumentam que elas são, frequentemente, determinadas socialmente, apesar de se apresentarem como subjetivas e únicas.

Segundo Novellino (2007), a cultura ocidental apresenta dois tipos de imagens: subjetivas e objetivas.

Imagens subjetivas apresentam uma perspectiva central, um ponto de vista, no qual o observador está apto a ver o participante representado na imagem apenas do ponto de vista em que a imagem foi construída. Imagens objetivas, por outro lado, não apresentam perspectiva alguma, nenhum ponto de vista, elas mostram tudo que o produtor da imagem acredita que há para ser mostrado, não se importando com a relação estabelecida com o observador. Essas imagens tendem a ocorrer em diagramas e mapas técnicos. Um cubo, por exemplo, num ângulo frontal, não mostrará todos os seus lados, suas dimensões, poderá nem ser reconhecido como cubo. (NOVELLINO, 2007, p. 77)

A função composicional refere-se aos significados obtidos através da "distribuição do valor da informação ou ênfase relativa entre os elementos da imagem" Unsworth (2004 apud NOVELLINO, 2007, p. 53). O significado composicional das imagens é realizado através de três sistemas inter-relacionados: o valor da informação, saliência e enquadramento.

O valor da informação é definido pela posição - esquerda, direita, superior, inferior, centro, margem - dos elementos na imagem. A saliência é usada para atrair a atenção do espectador, e se dá pelo posicionamento em primeiro plano ou plano de fundo, tamanho dos elementos, contrastes, etc. O enquadramento, por sua vez, tem a função de desconectar ou conectar elementos da imagem, agrupando-os ou os desagrupando-os.

A Gramática do Design Visual, de Kress e van Leeuwen, vê as imagens como uma composição de elementos que podem ser analisados individualmente, mas que, assim como a linguagem, só têm significado quando são integrados, ou seja, o significado das imagens visuais é determinado pela disposição dos seus elementos.

A respeito da carga semântica dos elementos constituintes das imagens, Jewitt e Oyama (2001) dizem que:

Conceitos como poder, interação, distância e envolvimento, etc. não são significados ocultos nas imagens; ao contrário, eles são significados potenciais, isto é, eles são os possíveis significados que serão ativados pelos produtores e espectadores de imagens. (JEWITT; OYAMA, 2001 apud LIU, 2013, p. 1260)

Logo, a descrição das imagens dos livros didáticos para os alunos com deficiência visual deve ter a função de ativar esses significados para auxiliar na construção do conhecimento desses alunos. 


\section{Diálogo entre AD e GDV}

Para que os alunos com deficiência visual tenham acesso a informações que vão além dos aspectos conotativo e denotativo das imagens, podendo, assim, fazer inferências a partir das representações simbólicas, interações sociais e estrutura composicional do texto imagético, propomos que as metafunções representacional, interacional e composicional, propostas por Kress e van Leeuwen na Gramática do Design Visual, sejam incorporadas ao processo de criação das audiodescrições para as imagens dos livros didáticos.

Para tanto, apresentamos a seguir parte do quadro comparativo das técnicas de descrição de imagens feitas pelos procedimentos da Audiodescrição e pela Gramática do Design Visual, elaborado por Camila da Silva Gonzaga em sua dissertação de mestrado.

\begin{tabular}{|l|l|}
\hline \multicolumn{2}{|c|}{ Pontos de Diferença da GDV e Audiodescrição } \\
\hline \multicolumn{1}{|c|}{ GDV } & \multicolumn{1}{c|}{ Audiodescrição } \\
\hline 1 - Analisa a imagem. & Descreve a imagem. \\
\hline $\begin{array}{l}\text { 2- Analisa o modo como os elementos representados se } \\
\text { combinam. }\end{array}$ & $\begin{array}{l}\text { Descreve os elementos de forma clara, objetiva e } \\
\text { didática. }\end{array}$ \\
\hline $\begin{array}{l}\text { 3- Tem a finalidade de identificar os princípios do do } \\
\text { funcionamento das imagens dentro do contexto social, } \\
\text { histórico e cultural. }\end{array}$ & $\begin{array}{l}\text { Tem a finalidade de descrever os elementos } \\
\text { relevantes, considerando os aspectos históricos e } \\
\text { culturais para promover a acessibilidade às } \\
\text { pessoas com deficiência. }\end{array}$ \\
\hline
\end{tabular}

Fonte: Quadro comparativo elaborado por Camila da Silva Gonzaga, embasado na Gramática do Design Visual. (KRESS; VAN LEEUWEN, 2006) e Técnicas de Audiodescrição do Mecdaisy (BRASIL, 2012).

A partir do quadro comparativo acima é possível observar a importância de incrementar as audiodescrições das imagens dos livros didáticos propostas pela Nota Técnica 21, do MEC, com as funções da Gramática do Design Visual, de Kress e van Leeuwen, para que as audiodescrições tenham, além de aspectos descritivos, aspectos analíticos, permitindo aos alunos com deficiência visual uma compreensão mais abrangente do papel comunicacional da linguagem visual.

Foram encontradas pesquisas que utilizam a GDV para analisar possíveis relações entre texto visual e texto verbal no campo do letramento visual em EAD, (CARVALHO; 
ARAGÃO, 2015); evidenciar elementos constitutivos da imagem na construção de sentido em livros de língua estrangeira (ARAÚJO, 2011); para analisar o letramento visual e a exploração de textos multimodais (BARBOSA; ARAÚJO, 2014), entre outras. Na articulação com a $A D$, apenas uma pesquisa de mestrado que usa a GDV foi encontrada. A GDV, nesse contexto, é utilizada para a elaboração de proposta didático-pedagógica para professores que lidam com alunos com deficiência visual (GONZAGA, 2015). Portanto, até o momento, não foi encontrada qualquer pesquisa que proponha a incorporação dos princípios da GDV à elaboração das audiodescrições das imagens dos livros didáticos.

Incorporar as metafunções de análise da GDV aos procedimentos de descrição que orientam as audiodescrições pode ampliar a capacidade de construção do conhecimento do aluno com deficiência visual. Essa junção lhe proporcionará uma experiência mais próxima da que tem o aluno vidente, uma vez que, além de aspectos descritivos, as audiodescrições trarão também aspectos analíticos ligados à carga simbólica e ideológica das imagens.

Os livros didáticos estão repletos de imagens de todos os gêneros. Elas exercem funções diversas, desde ilustrar ou complementar o conteúdo dos textos escritos até servir como a principal fonte de informação para a resolução de questões ou apresentação de tópicos. O grande desafio é proporcionar, aos alunos com deficiência visual, uma maior apropriação do objetivo comunicacional das imagens, o que Ihes permitirá uma maior autonomia no exercício do conhecimento subjetivo.

\section{Considerações finais}

É fato que as imagens estão cada vez mais presentes no nosso dia-a-dia, comunicando tanto ou mais que os textos verbais nos diversos meios de comunicação. Tal constatação nos leva, constantemente, a utilizar vários dos nossos sentidos para chegarmos a um entendimento mais abrangente do que essas imagens querem comunicar.

Boa parte das informações sobre as imagens que chegam ao público com deficiência visual é uma mera descrição delas mesmas, limitando seu escopo de abstração.

No contexto escolar, os alunos com deficiência visual utilizam os mesmos livros didáticos que os alunos videntes. Além disso, são submetidos às mesmas atividades 


\section{DOI: $10.5902 / 198468627720$}

pedagógicas e ao mesmo sistema de avaliação. Oferecer aos alunos deficientes visuais descrições que abranjam aspectos simbólicos e ideológicos das imagens amplia as suas possibilidades de apropriação do conhecimento.

Logo, a partir do que foi abordado neste artigo, percebe-se a necessidade da expansão deste estudo no sentido de incorporar as metafunções de análise das estruturas das imagens às audiodescrições que acompanham as versões digitais das imagens dos livros didáticos distribuídos pelo Programa Nacional do Livro Didático (PNLD).

\section{Referências}

American Council of the Blind. Audio Description Standards. Disponível em: <http://www.acb.org/adp/docs/ADP_Standards.doc z. Acesso em: 27/10/2010.

ARAÚJO, R. D. Gramática Visual: Trazendo à Visibilidade Imagens do Livro Didático de LE. Signum: Estudos da Linguagem, Londrina, n. 14/2, p. 61-84, 2011. Disponível em: <http://www.uel.br/revistas/uel/index.php/signum/article/view/8534/9583>. Acesso em: 15 out. 2016.

\section{Audio Description Coalition. In: Standards for Audio Description and Code of Professional Conduct for Describers. 2008.}

BARBOSA, V. S.; ARAÚJO, A. D. Multimodalidade e Letramento Visual: um estudo piloto de atividades de leitura disponíveis em sítio eletrônico. Revista da Anpoll, Florianópolis, n. 37, p. 17-36, 2014. Disponível em: < https://revistadaanpoll.emnuvens.com.br/revista/article/view/824/781>. Acesso em: 16 out. 2016.

BEZERRA, A.; PORPINO, K. de O. O letramento visual como experiência estesiológica. Holos, Rio Grande do Norte, ano 31, v. 3, 2015. Disponível em: <http://www.rbtv.associadosdainclusao.com.br/index.php/principal/article/view/27/20>. Acesso em: 10 nov. 2015.

BRASIL. Lei do Livro n 10.753, de 30 de outubro de 2003. Da Política Nacional do Livro. Art. 1, Inciso XII. Disponível em: <http://presrepublica.jusbrasil.com.br/legislacao/98248/politicanacional-do-livro-lei-10753-03\#art-1--inc-XIl>. Acesso em: 15 jun. 2013.

Decreto no 186, de 2008. Aprova o texto da Convenção sobre os Direitos das Pessoas com Deficiência. $\quad$ Disponível em: <http://www.planalto.gov.br/ccivil_03/constituicao/Congresso/DLG/DLG-186-2008.htm>. Acesso em: 17 jun. 2013.

Decreto no 7.084, de 27 de janeiro de 2010. Dos programas de material didático. Art. 28. Disponível em: $<$ http://www.planalto.gov.br/ccivil_03/_Ato20072010/2010/Decreto/D7084.htm>. Acesso em: 15 jun. 2013. 
DOI: $10.5902 / 198468627720$

Nota Técnica $n^{\circ} 21$, de 10 de abril de 2012. Das orientações para descrição de imagem na geração de material digital acessível - Mecdaisy. Disponivel em: $<$ http://portal.mec.gov.br/index.php?option=com_docman\&view=download\&alias=10538nota-tecnica-21-mecdaisy-pdf\&category_slug=abril-2012-pdf\&ltemid=30192>. Acesso em: 02 de junho de 2015.

Decreto $n^{\circ}$ 9.099, de 18 de julho de 2017. Dispõe sobre o Programa Nacional do Livro e do Material Didático. Disponível em: <http://www.planalto.gov.br/ccivil_03/_Ato20152018/2017/Decreto/D9099.htm\#art29>. Acesso em: 07 de abril de 2018.

CARVALHO, S. A.; ARAGÃO, C. de O. Os Caminhos do Letramento Visual: uma análise de material didático virtual. Revista Estudos Anglo Americanos, n. 44, p. 9-34, 2015. Disponível em: <http://reaa.ufsc.br/index.php/reaa/article/view/1274/662>. Acesso em: 12 out. 2016.

CAT - Comitê de Ajudas Técnicas. Secretaria Especial dos Direitos Humanos. Ata da Reunião VII, de dezembro de 2007. Disponível em: < http://www.pessoacomdeficiencia.gov.br/app/sites/default/files/publicacoes/livro-tecnologiaassistiva.pdf >. Acesso em: 20 jun. 2014.

FRANCO, E. P. C. et al. Audiodescrição para Além da Visão: um estudo piloto com alunos da APAE. In: ARAÚJO, V. L. S.; ADERALDO, M. F. (Org.). Os novos rumos da pesquisa em audiodescrição no Brasil. Curitiba: CRV, 2013. p. 201-211.

German AD Guidelines. In: A Comparative Study of Audio Description Guidelines Prevalent in Different Countries. RNIB, 2010. p. 20-60.

GONZAGA, C. da S. Uma perspectiva de trabalho didático com leitura e interpretação de texto multimodal para alunos com cegueira na escola regular. Dissertação de Mestrado em Letras. Universidade Federal da Bahia, 2015. 234 f.

HALLYDAY, M.A.K. An Introduction to Functional Grammar. 1. ed. London: Edward Arnold, 1985.2. ed. London: Edward Arnold, 1994.

MATHIESSEN, C.M.I.M. Introduction to Functional Grammar. 3. ed. London: Edward Arnold, 2004. ITC Guidance on Standards for Audio Description. Disponível em: <http://www.msradio.huji.ac.il/narration.doc>. Acesso em: 15/11/2010.

JEWITT, C.; OYAMA, R. Visual Meaning: A Social Semiotic Approach. In VAN LEEUWEN, T.; JEWITT, C. (Eds.) Handbook of Visual Analysis. London: Sage, 2001, p. 134-156.

KRESS, G.; VAN LEEUWEN, T. Reading images: the grammar of visual design. 1. ed. London: Routledge, 1996.2. ed. London: Routledge, 2006.

LIEBEL, V. Reconstruindo Imagens - o método documentário de análise. In: XV CONGRESSO BRASILEIRO DE SOCIOLOGIA. 2011, Curitiba. Anais do XV Congresso Brasileiro de Sociologia. Curitiba-PR, 2011. 
DOI: $10.5902 / 198468627720$

LIU, J. Visual Images Interpretive Strategies in Multimodal Texts. Journal of Language Teaching and Research, Finland, v. 4, n. 6, p. 1259-1263, 2013. Disponível em: $<$ http://www.academypublication.com/issues/past/jttr/vol04/06/15.pdf>. Acesso em: 18 out. 2016.

NOVELLINO, M. O. Fotografias em livro didático de inglês como língua estrangeira: análise de suas funções e significados. Dissertação de Mestrado em Letras. Pontifícia Universidade Católica do Rio de Janeiro, 2007. 271 f.

PEREZ, W. Gramática Visual: A Linguagem do Visível. Tese de Doutorado. Universidade Federal de Santa Catarina, 2008. $311 \mathrm{f}$.

SNYDER, J. The Visual Made Verbal: A Comprehensive Training Manual and Guide to the History and Applications of Audio Description. Arlington: American Council of the Blind, 2014.

UNE 153020. In: A Comparative Study of Audio Description Guidelines Prevalent in Different Countries. RNIB, 2010. p. 12-20.

\section{Correspondência}

Deise Mônica Medina Silveira - Universidade Federal da Bahia (UFBA), Rua Barão de Jeremoabo, CEP: 40170-115Ondina, Salvador, Bahia, Brasil.

Th is work is licensed under a Creative Commons Attribution-NonCommercial 4.0 International (CC BY-NC 4.0) 